\title{
Renal transplantation in the Middle East: strengths, weaknesses, opportunities and threats [SWOT] analysis
}

\begin{abstract}
Renal Transplantation is the best option for treating patients with end stage renal disease. Transmitting such success in to a special area like the Middle East is challenging. Transplantation in the Middle East is shaped by shaped by the prevailing religious socioeconomic and health indicators in the different countries. Living organ donation is the most widely practiced type of donation in the Middle East. However some countries like Saudi Arabia, Iran, Egypt, and Kuwait established their legislations for deceased donation.

Renal transplantation in this area has strengths, weaknesses, opportunities and threats. The strength is the intention to have a better future, the established transplantation programs and the possible positive impact of the Middle East Society for Organ Transplantation [MESOT] to gather all individual programs in to a functioning network. Low health spending, poorly developed infrastructures, inadequate dialysis programs, organ shortage and commercial transplantation are the main weaknesses. The opportunity lies in investing the existing models of organ donation, incorporation of Islamic fatwa, governmental legislations, media and technology to increase awareness at large toward transplantation. Deceased donation has the potential to widen donor's pool but it needs acceptance, and regulation. The threat is the recently changing geopolitics and shifted economy with its negative impact by increasing organs black market. Middle East is endemic in certain transplantation related infections like viral hepatitis and TB which detrimentally affect patient and graft survival.
\end{abstract}

Volume 2 Issue 2 - 2015

\author{
Ala Ali, ' Achraf Hendawy ${ }^{2}$ \\ 'Nephrology \& Renal Transplantation Center,The Medical City \\ Teaching Hospital, Iraq \\ ${ }^{2}$ Consultant Nephrologist, Ministry of Health, Egypt
}

Correspondence: Ala Ali, Nephrology \& Renal Transplantation Center, The Medical City Teaching Hospital, PO Box 53205, Bab Al-Mudhum 10047, Baghdad, Iraq, Tel 009647706049163, Email ala1975@gmail.com

Received: October 3, 20I4 | Published: March 13, 2015

Keywords: renal transplantation, organ donation, middle east, SWOT analysis

Abbreviations: MESOT, middle east society for organ transplantation; DCD, donation after cardiac death; GCC, gulf cooperation council; DD, deceased donors; SCOT, Saudi center for organ transplantation

\section{Historical overview}

The first renal transplant in the Middle East was in $1967^{1}$ in Iran. The Arab world followed in Jordan and Iraq in 1972 and 1973 respectively. Egypt joined the line in 1976 and Saudi Arabia started in $1979 .{ }^{2-4}$ Currently, all countries in this region have active renal transplantation programs with variable capacities according to local logistics and policies. Living donation is the most widely practiced type of donation in the Middle East. However deceased donation is not well established. Few countries approved laws for deceased donation as in KSA in 1985, Iran in 2000, and Egypt in 2010. ${ }^{1,45}$ The Iranian model startedyears ago is renal graft donation from living, genetically unrelated people. This program had a high volume for donation (17pmp/year). However organs from donation after cardiac death (DCD) can increase the donor pool by $15-25 \%{ }^{6}$ The registered total kidney transplants in Middle East countries from January to December 2012 were about 8000 (6611 live donations and 1379 deceased donations).

On 2008, Declaration of Istanbul on Organ Trafficking and Transplant Tourism emerged as an international act to protect vulnerable populations (such as illiterate and impoverished persons, undocumented immigrants, prisoners, and political or economic refugees) in resource-poor countries. ${ }^{8}$ The increasing number of such endangered population in nowadays Middle East makes it difficult to apply and obey the proposals of this document.

\section{SWOT analysis}

It is a structured planning method used to evaluate the strengths, weaknesses, opportunities, and threats involved in a project or in a business venture. It is a strategic planning tool that separates influences on a business's future success into internal and external factors. It is an important technique which provides quality information to the managers to take effective decision for future development of organization. ${ }^{9}$ It's unusual to apply business analytics in to medical field, but searching for key word, SWOT analysis; on pub med revealed 215 articles. An interesting SWOT analysis of Banff classification published in American journal of transplantation. ${ }^{10}$

From renal transplantation perspectives, the main objectives of SWOT analysis are to improve patient care, workforce recruitment, analysis and management of the existing and future transplantation data. This paper presents such an informal 'SWOT' analysis of renal transplantation in the Middle East. The aim is to improve our practice via better understanding of the current status and to have applicable plan for future.

\section{Strengths}

The main point of strength is our good intention to have better future. There is a multitude of skilled transplant nephrologists and surgeons working in such low resources setting. This is the key engine 
of progress. The existing transplantation programs in all countries represent the base on which we can build up using knowledge, modern technology and the cost advantages of wealthy countries. In addition, social proximity and bonding between the people of this region should help to increase organ donation for both living related and unrelated transplantation. The presence of the Middle East Society of Organ Transplantation (MESOT) must have an active influence in the efforts of MESOT countries to plan for future of renal transplantation.

\section{Weaknesses}

There are common features of renal transplantation in the Middle East countries that include inadequate preventive medicine, uneven health infrastructure, poor maintenance dialysis programs, poor awareness in the medical community and public at large of the importance of the organ donation and transplantation, poor government support of organ transplantation, and lack of well trained manpower and no effective health insurance. ${ }^{6}$

Health care delivery in the Middle East is dominated by the public sector. The access to health coverage is limited and distribution of health services is skewed towards urbanized areas and higher socioeconomic status. With the exception of the Gulf Cooperation Council (GCC) countries, most Middle East countries show high dependence on direct, out-of-pocket payments by households, which account for more than half of the total health spending. In spite of such inequality in health spending, all countries share the same challenge of growing and aging population and consequently increasing total health care expenditures per capita. This is perfectly applicable to ESRD and the increasing need for renal transplantation. The number of patients on waiting lists for transplantation increases with time, and the gap is growing between supply and demand of organs. ${ }^{11,12}$

Still there are no fully developed renal registries to enable accurate estimates of these numbers and there are no properly formulated policies and guidelines beside the absence of meaningful research in the tertiary health units. In the absence of strict regulations; patients seek commercial transplantation most of the time with increasing disparities in the access for transplantation resulting in ethical and legal challenges with more crimes of organ trafficking. ${ }^{5}$ Commercial organ donation comes at the expense of, not in addition to, unpaid, 'altruistic' donation. Commercial donation has downsides beyond its dangers to the individual donor and recipient. Reliable information outcome data from both the donors and recipients of commercial donation are sparse and fragmentary and likely underestimate the true complication rate. Medical staff that engage in commercial organ transplantation are not free from serious bad consequences like withdrawal of academic recognition or even prosecution..$^{13,14}$

\section{Opportunities}

Two interesting models of organ donation in the Middle East need to be considered and could be developed, the Iranian and Saudi models. By incorporating governmental legislations and Islamic fatwa it will be possible to increase donors pool by incentives policies for living donors and with more understanding and usage of applicable definitions of brain death and informed consent deceased donation will add to the donors pool. ${ }^{1,15,16}$ The "Iran Model", supported by the government for LURD transplantation, under this model, the donor receives financial compensation from the recipient as well as the government or the charity, along with non-monetary bonuses such as free health insurance. The government also offers heavily subsidized immunosuppressive therapy to the recipient. Currently, Iran has no kidney transplant waiting list and more than 50 percent of patients with end-stage renal disease are living with a functioning graft. ${ }^{1}$

To the best of our knowledge there is no national transplant registry in Iran to report the short- and long-term results of transplantation in all transplant recipients and kidney donors. Most renal transplant teams report their own results as single-center experiences. Ethicists suggested that this model is not flawless. One of their concerns is that only poor people will donate and even with regulations there is a possible black market. ${ }^{17}$ Incentives for organ donation, currently prohibited in most countries. Two caveats emerged: ethical principles that justify this prohibition and whether incentives would do more good than harm. A possible future plan is to have trials in the Middle East taking in considerations the challenges of Iranian model. This, perhaps, may lead to a regulated incentives system, modified Iranian model. Critical elements of such a system would be protection, regulation, oversight and transparency under the auspices of the appropriate government or government-recognized body. ${ }^{6,18,19}$

The Saudi model includes a national organ procurement center, Saudi Center for Organ Transplantation [SCOT]; as a governmental agency to supervise organ donation and transplantation. It coordinates the process of organ donation between the donating hospitals and transplant centers [coordinators, consents, harvesting teams]. Furthermore, it applies strategies to increase awareness to the community of the importance of donation and transplantation. ${ }^{6,15}$ The Pakistani model is an interesting funding model for management of end-stage organ failure in the developing countries adopted in a major center in Sind-Pakistan [SIUT]. The government pays 40$50 \%$ for the renal services and the community pays the rest. The activity of SIUT includes free provision of medications including immunosuppressant's, long-life follow up and rehabilitation of transplant recipients. A vocational training program is open to all who wish to avail themselves of the facility. In special cases where they cannot return to their professions, the institute provides training or financial support..$^{20}$ The results of living organ donation in Pakistan are very good with an overall graft survival rates from $96 \%$ to $91 \%$ at 1 year and $87 \%$ to $68 \%$ at 5 years due to above mentioned reasons beside integrated dialysis and transplantation. ${ }^{21}$ By this model there is acceptance of transplantation in the society through more society sharing in funds and more accountability to supporters. Implementation of social efforts in to the program will lead to development of well trained manpower and improves human resources. ${ }^{6,20}$

In 2011, Qatar started what is called a Doha model. With increasing number of non citizen residents to the Gulf Cooperation Council (GCC) countries there will be a real need to clarify citizenship and the human rights to receive the best care in a transparent way.

The main features of this model include:

i. All legal residents of Qatar have an equal right to access deceased donor organs and transplantation regardless of their citizenship status.

ii. No prioritization in organ allocation is given to Qatari citizens.

iii. A multilingual and multicultural education and promotional program about donation has been implemented to engage the diverse national community's resident within Qatar.

Financial incentives or fungible rewards for living or deceased donation are prohibited. ${ }^{22}$ 
It will take some time to evaluate and assess the long term kidney donors and recipients outcome. Islam has its economic jurisprudence and this can be applicable in funding the existing transplant programs in Middle East countries. Zakat "that which purifies" is the practice of taxation and redistribution, imposed upon Muslims on their income and wealth. It is a form of obligatory alms giving, and the collected amount is paid to poor Muslims, to zakat collectors. In other word, according to God's wish, must be channeled towards the community. ${ }^{23}$ This will not increase funds only but will enhance awareness and altruism for donation.

Improving the present national transplant registries could be the base of establishing a future network for organ sharing in the Middle East. This in turn may regulate organ transport and can implement new concepts in organ donation like paired donation and regulations toward more acceptance of extended criteria living donors. ${ }^{24}$ Application of the concept of presumed consent is another opportunity to have in order to increase donor's pool. In countries that have accepted the concept of presumed consent, such as Spain, there is the highest number of organs from deceased donors (DD). In Spain the number of deceased donors per year is 34/million population, whereas in Saudi Arabia 5/million, and Turkey 2.5/million. Certainly, to apply presumed consent there should be unified crystal clear applicable definitions of brain death. Education of ICU personnel and transplant coordinators on how to apply it should run in parallel. ${ }^{24}$

\section{Threats}

On the basis of our findings, it is necessary to prolong the followup for detection of late relapses or failures in patients who underwent initial sub optimal retroperitoneal surgery. Recurrence residual retroperitoneal of GCT disease must be treated with redo surgery, when chemotherapy previous surgery fails, thinking that can growth viable tumor teratoma. In this scenario it is the last chance cure for patients with advanced disease, although the overall survival rates is lower than initial RPLND. Clinical outcomes after repeat retroperitoneal surgery depend on re operative histology. Redo surgery is not a routine procedure, it is complex and it should be carried out in a specialized center in order to management possible Intraoperative complications.

\section{Conclusion}

Renal transplantation is hampered with obstacles in Middle East countries. Local experiences can be implemented into governmentally and society funded new, improved models that can help overcome current obstacles. The Achill's tendon is the awareness of the public, the medical community, and the governments about the importance of organ donation and transplantation are indispensible to overcome the current threats.

\section{Acknowledgements}

None.

\section{Conflict of interest}

The author declares no conflict of interest.

\section{References}

1. Einollahi B, Taheri S. Renal transplantation practice in Iran and the middle east: report from Iran and a review of the literature. Ann Transplant. 2008;13(1):5-14.
2. Abomelha MS. Renal failure and transplantation activity in the Arab world. Arab Society of Nephrology and Renal Transplantation. Nephrol Dial Transplant. 1996;11(1):28-29.

3. Rifat UN. Kidney Transplantation in Iraq. Saudi J Kidney Dis Transpl. 2006;17(3):399-400

4. Al Sayyari AA. The History of Renal Transplantation in the Arab World: A View From Saudi Arabia. Am J Kidney Dis. 2008;51(6):1033-1046.

5. Hamdy S. The Organ Transplant Debate in Egypt: a Social Anthropological Analysis. Droit et Cultures. 2010;59(1):357-365.

6. Shaheen FA. Organ Donation in the Middle East Countries. Ethn Dis. 2009;19(1 Suppl1):16-17.

7. Masri M, Haberal M. Solid Organ Transplantation Activity in MESOT Countries. Exp Clin Transplant. 2013;11(2):93-98.

8. International Summit on Transplant Tourism and Organ Trafficking. The Declaration of Istanbul on Organ Trafficking and Transplant Tourism. Clin J Am Soc Nephrol. 2008;3(5):1227-1231.

9. Anil M, Sudar GB, Tej AP, et al. Antecedents and Consequences of Marketing Strategy Making: A Model and A Test. Journal of Marketing. 1999;63(2):18-40.

10. Mengel M, Sis B, Halloran PF. SWOT Analysis of Banff: Strengths, Weaknesses, Opportunities and Threats of the International Banff Consensus Process and Classification System for Renal Allograft Pathology. Am J Transplant. 2007;7(10):2221-2226.

11. 2014 Global health care outlook, Shared challenges, shared opportunities, Deloitte.

12. Mena Health Sector Brief-September 2010, The World Bank.

13. Danovitch GM. The high cost of organ transplant commercialism. Kidney Int. 2014;85(2):248-225.

14. Danovitch GM, Chapman J, Capron AM, et al. Organ trafficking and transplant tourism: the role of global professional ethical standards-The 2008 Declaration of Istanbul. Transplantation. 2013;95(11):1306-1312.

15. Shaheen FA, Souqiyyeh MZ. How to Improve Organ Donation in the MESOT Countries. Ann Transplant. 2004;9(1):19-21.

16. Shaheen FA, Souqiyyeh MZ. Current status of renal transplantation in the Kingdom of Saudi Arabia. Transplant Proc. 2004;36(1):125-127.

17. Ghods AJ, Savaj S. Iranian Model of Paid and Regulated Living-Unrelated Kidney Donation. Clin J Am Soc Nephrol. 2006;1(6):1136-1145.

18. Matas AJ, Satel S, Munn S, et al. Incentives for Organ Donation: Proposed Standards for an Internationally Acceptable System. Am J Transplant. 2012;12(2):306-312.

19. Matas A, Ambagtsheer JA, Gaston R, et al. A realistic proposal-incentives may increase donation-we need trials now! Am J Transplant. 2012;12(7):1957-1958.

20. Rizvi SA, Naqvi SA, Zafar MN, et al. A Renal Transplantation Model for Developing Countries. Am J Transplant. 2011;11(11):2302-2307.

21. Rizvi SA, Naqvi SA, Zafar MN, et al. Kidney transplantation model in a low-resource country: an experience from Pakistan. Kidney Int Suppl. 2013;3(2):236-240.

22. Martin D, Fadhil RA. The doha model of organ donation and transplantation: thinking beyond citizenship. Griffith journal of law \& human dignity. 2014;2(2):293-329.

23. Medani Ahmed, Sebastian Gianci. Encyclopedia of Taxation and Tax Policy. p. 479-481.

24. Abouna GM. Organ Shortage Crisis: Problems and Possible Solutions. Transplant Proc. 2008;40(1):34-38. 